International Journal of Statistics and Systems

ISSN 0973-2675 Volume 16, Number 1 (2021), pp. 37-43

(C) Research India Publications

https://dx.doi.org/10.37622/IJSS/16.1.2021.37-43

\title{
Markovian behaviour of Jammu Rainfall
}

\author{
Ameena Rajput, Devya Mahajan and Parmil Kumar*
}

Department of Statistics University of Jammu, $J$ and $K$, India.

Daily rainfall data recorded at the meteorological observatory of Sher-E-Kashmir University of Agricultural Sciences and Technology, Jammu for period 1987-2013 was used for estimating the transition probabilities of first and second order

Table 1: DISTRIBUTION OF RAINFALL AT JAMMU

\begin{tabular}{|c|c|c|c|}
\hline YEAR & $\begin{array}{c}\text { RAINFALL } \\
\text { ANNUAL }(\mathrm{mm})\end{array}$ & $\begin{array}{c}\text { JUNE-OCT } \\
(\mathrm{mm})\end{array}$ & $\begin{array}{c}\text { AS \% OF } \\
\text { ANNUAL } \\
\text { RAINFALL }\end{array}$ \\
\hline 1987 & 837.5 & 541.8 & 64.6925 \\
\hline 1988 & 1319.8 & 1045.6 & 79.2241 \\
\hline 1989 & 762.1 & 566.4 & 74.3209 \\
\hline 1990 & 1824.9 & 1097.7 & 60.1512 \\
\hline 1991 & 1092.2 & 874.9 & 80.1043 \\
\hline 1992 & 1119.2 & 776.1 & 69.3441 \\
\hline 1993 & 1014.2 & 817.2 & 80.5758 \\
\hline 1994 & 1362.7 & 1191.3 & 87.4220 \\
\hline
\end{tabular}

\footnotetext{
* (Corresponding author).
} 


\begin{tabular}{|c|c|c|c|}
\hline YEAR & $\begin{array}{c}\text { RAINFALL } \\
\text { ANNUAL (mm) }\end{array}$ & $\begin{array}{c}\text { JUNE-OCT } \\
(\mathbf{m m})\end{array}$ & $\begin{array}{c}\text { AS \% OF } \\
\text { ANNUAL } \\
\text { RAINFALL }\end{array}$ \\
\hline 1995 & 1078.6 & 847 & 78.5277 \\
\hline 1996 & 1486.2 & 1311.7 & 88.2586 \\
\hline 1997 & 1462.1 & 1194.8 & 81.7180 \\
\hline 1998 & 1139.6 & 868.8 & 76.2372 \\
\hline 1999 & 875 & 762 & 87.0857 \\
\hline 2000 & 1061.1 & 816.8 & 76.9767 \\
\hline 2001 & 948.5 & 847.4 & 89.3410 \\
\hline 2002 & 830.3 & 748.5 & 90.1481 \\
\hline 2003 & 1455.3 & 1164.1 & 79.9903 \\
\hline 2004 & 837.9 & 636.8 & 75.9995 \\
\hline 2005 & 1112.6 & 702.9 & 63.1763 \\
\hline 2006 & 1236.3 & 1002.1 & 81.0563 \\
\hline 2007 & 1312.4 & 844.9 & 64.3782 \\
\hline 2008 & 1339.4 & 1100.9 & 82.1935 \\
\hline 2009 & 800.7 & 583.1 & 72.8237 \\
\hline 2010 & 1343.8 & 1169.3 & 87.0144 \\
\hline 2011 & 1478 & 1251 & 84.6414 \\
\hline 2012 & 1397.1 & 1082.9 & 77.5105 \\
\hline 2013 & 1743.3 & 1481.7 & 84.9939 \\
\hline AVERAGE & 1195.215 & 938.063 & 78.4401 \\
\hline
\end{tabular}

(description table I)?????????????? 
The territory of the State J\&K lies between degree of latitude from 32.17 to 36.58 North. In Jammu, the climate is typically monsoonal, with average 40 to $50 \mathrm{~mm}(1.6$ to 2 inches) of rain per months between January and March. Our study confines to study the rainfall pattern of Jammu region only. In the hot season, Jammu city is very hot and can reach up to $\mathbf{4 0}^{\circ} \mathbf{c}$ whilst in July and August, very heavy though erratic rainfall occurs with monthly extremes of up to 650 millimeters (25.5 inches),. In September, rainfall declines, and by October conditions are hot but extremely dry, with minimal rainfall and temperatures of around $29^{\circ} \mathrm{C}$ (Refer Graph 1). Jammu is located between 74 degree 24' and 75 degree 18' East longitude and 32 degree 50' and 33 degree 30' North latitude. Jammu district is spread over an area of 3097.89 sqkm and has a population of about 951373 as per the estimates of 2011. Jammu receives a rainfall of above $1,100 \mathrm{~mm}$ annually. About 80 per cent of average annual rainfall of Jammu occurs during south west monsoon period (June to October)(refer Table 1).

\section{Classification of States}

The information on weather's wet and dry behaviour has vital importance to all allied fields like insurance, agriculture, and industry etc. Once the rainfall process is adequately and appropriately modeled, the model can then be used in agricultural planning, may be able to aid in draught, soil erosion and flood predictions, impact of climate change studies, rainfall runoff modelling, crop growth studies and other important fields.

Based on daily rainfall occurrences, two weather conditions viz., Wet and Dry, are taken into consideration. A day is defined as a wet day if rainfall on that day exceeds or equals to $2.5 \mathrm{~mm}$ and a dry day, otherwise. The two States taken as wet and dry are denoted by 'w' and 'd', respectively.

\section{Estimated transition probabilities}

The transition probabilities are estimated using ???? for the Markov Chain of order one, two, three, four and five. The estimated transition probabilities for Markov chain of order one are defined as under:

$\mathrm{P}(\mathrm{w} / \mathrm{w}): \quad \operatorname{Pr}$ (actual day is wet, given that preceding day was wet)

$\mathrm{P}(\mathrm{d} / \mathrm{w}): \operatorname{Pr}($ actual day is dry, given that preceding day was wet $)=1-\mathrm{P}(\mathrm{w} / \mathrm{w})$

$\mathrm{P}(\mathrm{w} / \mathrm{d}): \quad \operatorname{Pr}$ (actual day is wet, given that preceding day was dry)

$\mathrm{P}(\mathrm{d} / \mathrm{d}): \quad \operatorname{Pr}($ actual day is dry, given that preceding day was dry $)=1-\mathrm{P}(\mathrm{w} / \mathrm{d})$

The estimated transition probabilities for Markov Chain of order two are defined as under: 
$\mathrm{P}(\mathrm{w} / \mathrm{w} \mathrm{w})$ : $\operatorname{Pr}($ actual day is wet, given that preceding two days were in the order wet and wet)

$\mathrm{P}(\mathrm{w} / \mathrm{d} \mathrm{w}) \quad: \operatorname{Pr}($ actual day is wet, given that preceding two days were in the order dry and wet)

$\mathrm{P}(\mathrm{w} / \mathrm{w} \mathrm{d}) \quad$ : $\operatorname{Pr}($ actual day is wet, given that preceding two days were in the order wet and dry)

$\mathrm{P}(\mathrm{w} / \mathrm{d} \mathrm{d}) \quad$ : $\operatorname{Pr}($ actual day is wet, given that preceding two days were in the order dry and dry)

Other transition probabilities are obtained simply by subtracting from one, as under:

$\mathrm{P}(\mathrm{d} / \mathrm{w} \mathrm{w}) \quad=\quad 1-\mathrm{P}(\mathrm{w} / \mathrm{w} w)$

$\mathrm{P}(\mathrm{d} / \mathrm{d} \mathrm{w}) \quad=\quad 1-\mathrm{P}(\mathrm{w} / \mathrm{d} \mathrm{w})$

$\mathrm{P}(\mathrm{d} / \mathrm{w} \mathrm{d}) \quad=\quad 1-\mathrm{P}(\mathrm{w} / \mathrm{w} \mathrm{d})$

$P(\mathrm{~d} / \mathrm{d} \mathrm{d}) \quad=\quad 1-\mathrm{P}(\mathrm{w} / \mathrm{d} \mathrm{d})$

The estimated values of transition probabilities of order one are given in Table 2 and of order two in Table 3 for the period 1987-2013.

TABLE 2

ESTIMATED TRANSITION PROBALITIES BASED ON PRECEDING ONE DAY

(ORDER ONE)

$\operatorname{Wet}(=\mathrm{w}) \geq 2.5 \mathrm{~mm}$

$\operatorname{Dry}(=\mathrm{d})<2.5 \mathrm{~mm}$

\begin{tabular}{|c|c|c|}
\hline PRECEDING DAYS & $\begin{array}{c}\text { OBSERVATION } \\
\text { TABLE }\end{array}$ \\
\hline 1 & W & D \\
\hline W & 0.4211 & 0.5789 \\
D & & \\
\hline
\end{tabular}


TABLE 3

ESTIMATED TRANSITION PROBALITIES BASED ON PRECEDING TWO DAY

(ORDER TWO)

$\operatorname{Wet}(=\mathrm{w}) \geq 2.5 \mathrm{~mm}$

$\operatorname{Dry}(=d)<2.5 \mathrm{~mm}$

\begin{tabular}{|cc|c|c|}
\hline \multicolumn{2}{|c|}{ PRECEDING DAYS } & $\begin{array}{c}\text { OBSERVATION } \\
\text { TABLE }\end{array}$ \\
\hline 2 & 1 & W & D \\
\hline w & w & 0.4445 & 0.5555 \\
d & w & 0.4545 & 0.5455 \\
w & d & 0.2728 & 0.7272 \\
d & d & 0.1112 & 0.8888 \\
\hline
\end{tabular}

Table 2 shows the value of $P(w / w)$ as 0.4211 and $P(d / d)$ as .5789 , Table 3 gives the value of $\mathrm{P}(\mathrm{w} / \mathrm{w} \mathrm{w})$ as 0.4445 and $\mathrm{P}(\mathrm{d} / \mathrm{d} \mathrm{d})$ as 0.5555 . This shows that the probability that actual day is wet given that preceding days were wet, had been increasing as the number of preceding consecutive wet days are increased. Probability that actual day is dry given the preceding days were dry, has been decreasing as the number of preceding consecutive days are increased.

These estimates of transition probabilities, various properties of rainfall pattern can be studied and used by meteorologists, agricultural scientists and policy planners. These helps in proper planning of the resources and advisory to the farmers and other dependent on the rainfall. This way we can predict the rainfall probabilities in advance by using the markov chain model. Further study can be undertaken in the direction of authentication of the above claim. Also with the advent of modern computers higher order transition probabilities can be computed. 

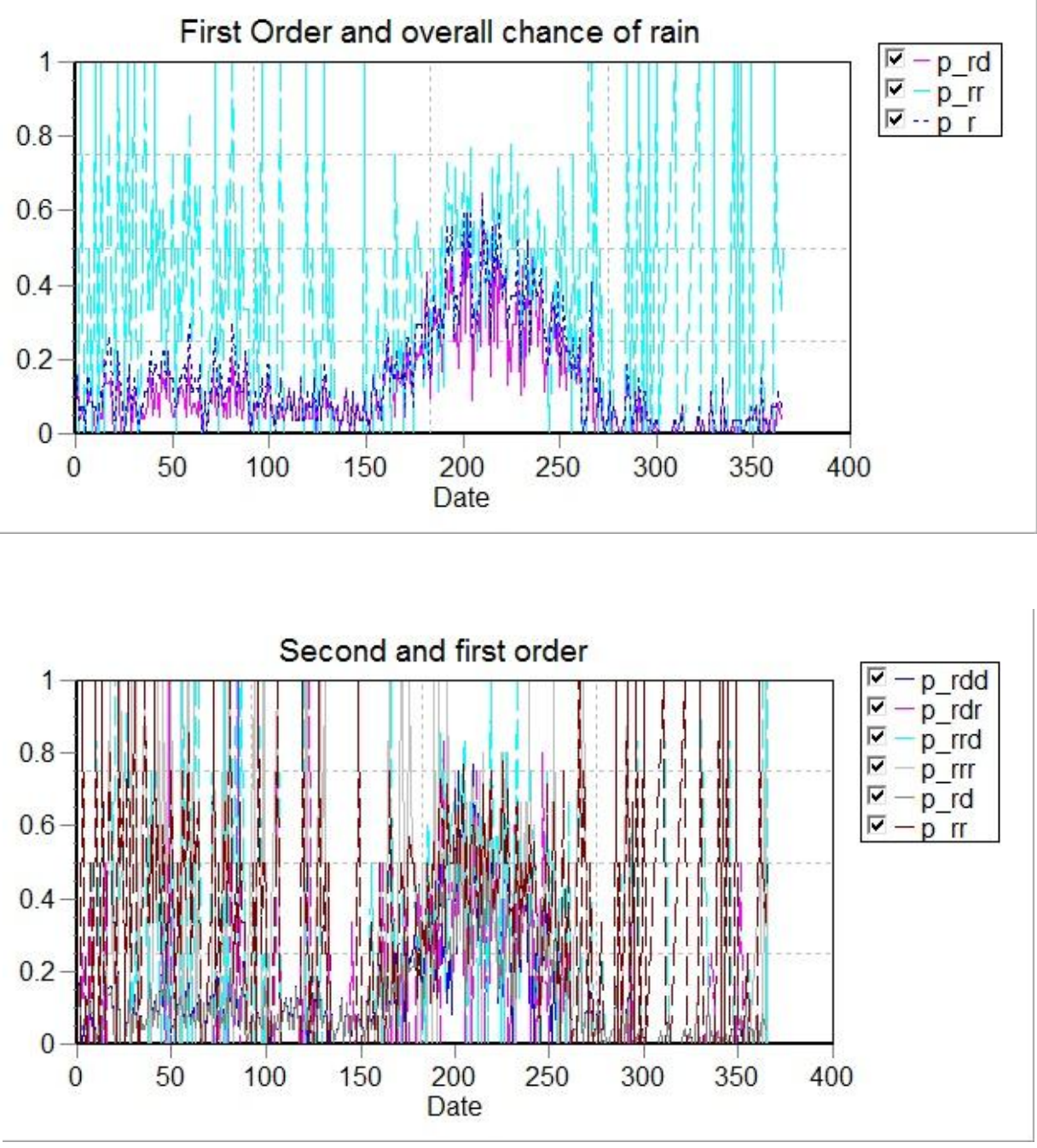

First and zero order

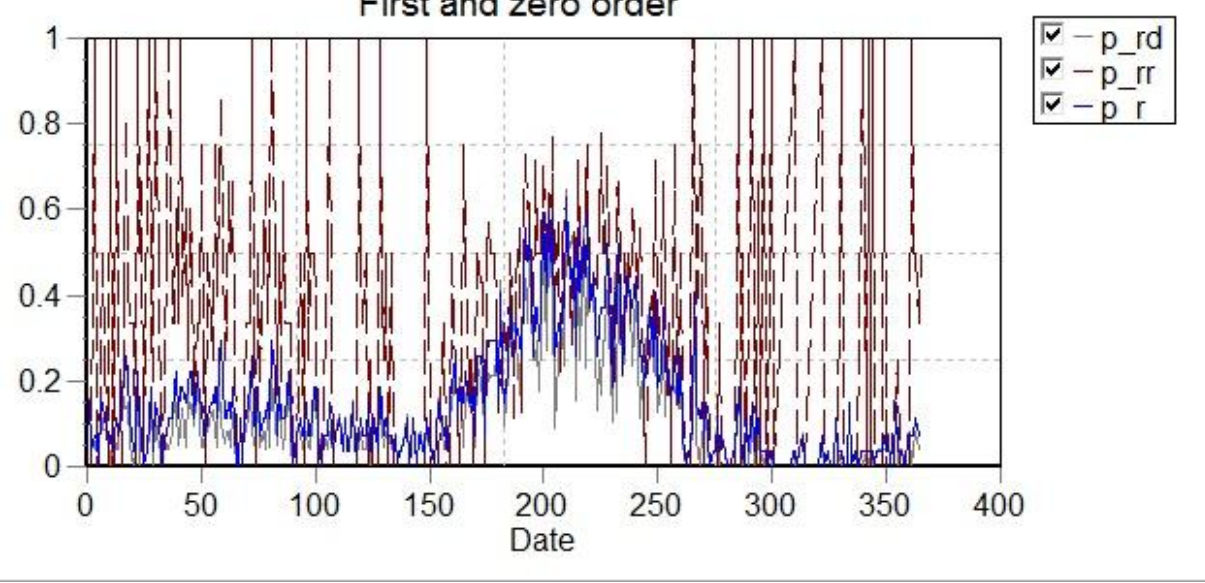



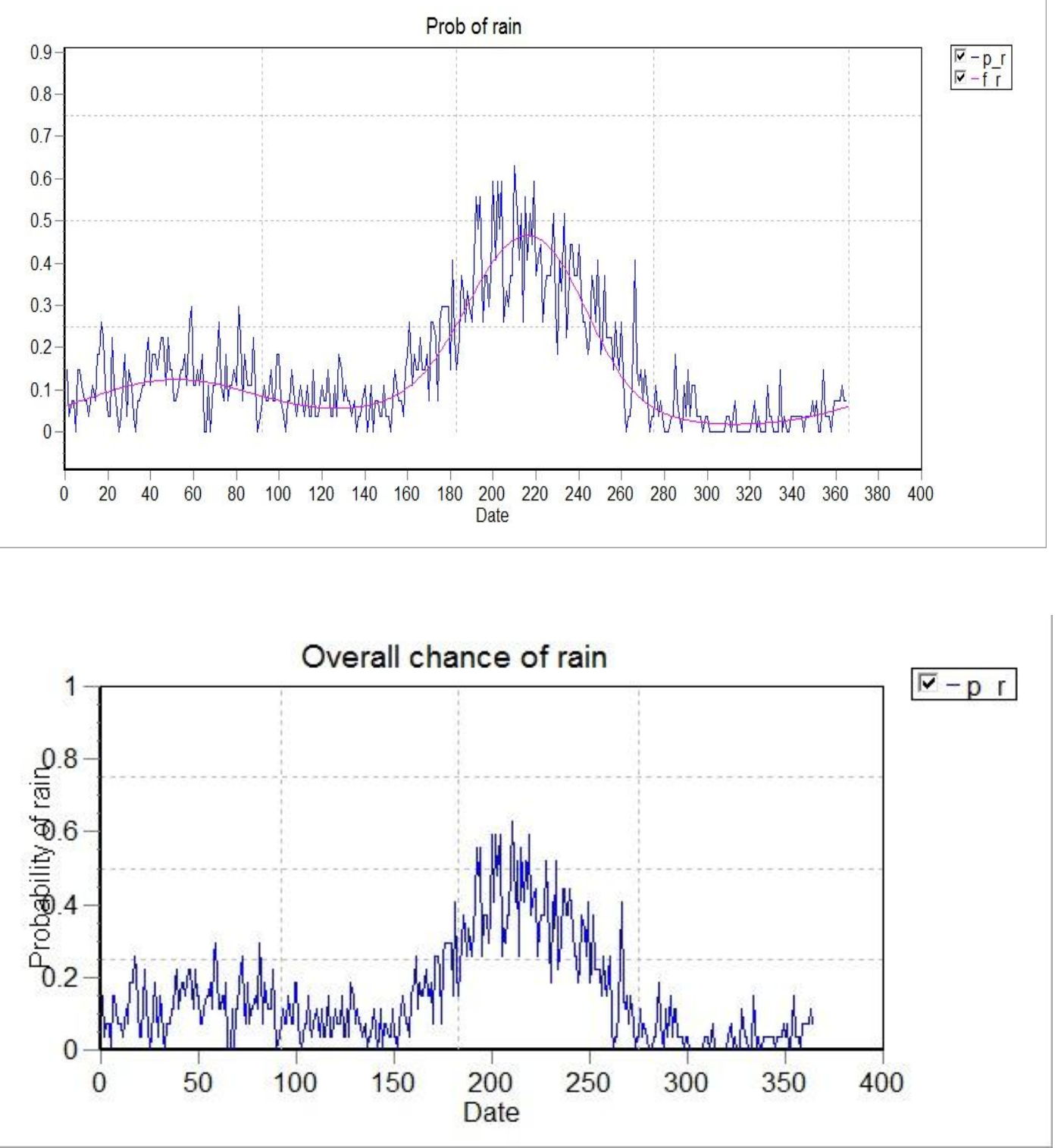

We have plotted the transition probabilities of different orders along with overall chance of rain in Fig I-V. It can be seen that chance of rain is peak around $200^{\text {th }}$ days of year i.e. end july (Fig I). So the possibilities of occurrence of flood is maximum during the period last week of july ( 7 days). So, planning can be made accordingly by the concerned departments of the govt. 
